with or without the use of retarding agents. The powders of this class are ballistite and filite, the former being in sheets, the latter in threads. Originally camphor was introduced, but its use has been abandoned, a small quantity of aniline taking its place.

Sir Frederick Abel and Prof. Dewar patented in 1889 the use of trinitrocellulose and nitroglycerine, for although, as is wellknown, this form of nitrocellulose is not soluble in nitroglycerine, yet by dissolving the bodies in a mutual solvent, perfect incorporation can be attained. Acetone is the solvent used in the preparation of "cordite," and for all ammunition except blank charges a certain proportion of vaseline is also added. The combustion of the powder without vaseline gives products so free from solid or liquid substances that excessive friction of the projectile in the gun causes rapid wearing of the rifling, and it is chiefly to overcome this that the vaseline is introduced, for on explosion a thin film of solid matter is deposited in the gun, and acts as a lubricant.

The proportion of the ingredients are :-

$\begin{array}{lccccccc}\text { Nitroglycerine } & \ldots & \ldots & \ldots & \ldots & 58 & \text { parts. } \\ \text { Gun-cotton } & \ldots & \ldots & \ldots & \ldots & \ldots & 37 & , \\ \text { Vaseline } & \ldots & \ldots & \ldots & \ldots & \ldots & 5 & ,,\end{array}$

Gun-cotton to be used for cordite is prepared as previously described, but the alkali is omitted, and the mass is not submitted to great pressure, to avoid making it so dense that ready absorption of nitroglycerine would not take place. The nitroglycerine is poured over the dried gun-cotton and first well mixed by hand, afterwards in a kneading machine with the requisite quantity of acetone for $3 \frac{1}{2}$ hours. A water jacket is provided, since on mixing the temperature rises. The vaseline is now added, and the kneading continued for a similar period. The cordite paste is first subjected to a preliminary pressing, and is finally forced through a hole of the proper size in a plate either by hand or by hydraulic pressure. The smaller sizes are wound on drums, whilst the larger cordite is cut off in suitable lengths, the drums and cut material being dried at $100^{\circ} \mathrm{F}$., thus driving off the remainder of the acetone.

Cordite varies from yellow to dark brown in colour according to its thickness. When ignited it burns with a strong flame, which may be extinguished by a vigorous puff of air. Macnab and Ristori give the yield of permanent gases from English cordite as 647 c.c., containing a much higher per cent. of carbon monoxide than the gases evolved from the old form of powder. Sir Andrew Noble failed in attempts to detonate the substance, and a rifle bullet fired into the mass only caused it to burn quietly.

Lyddite is probably the explosive which has received most notice during the past few months. In 1873 , Sprengel, in a paper read before the Chemical Society, stated that " picric acid alone contains a sufficient amount of oxygen to render it, without the help of foreign oxidisers, a powerful explosive when fired with a detonator. Its explosion is almost unaccompanied by smoke."

Picric acid was first prepared by Hausmann in 1878 , by treating indigo with nitric acid. It may be made by the direct nitration of phenol (carbolic acid), but a better result is obtained by first dissolving the phenol in sulphuric acid, forming phenol sulphonic acid, which is dissolved in water, and nitrating this compound with nitric acid $\left(\mathrm{I}^{*} 4\right)$. On cooling, the picric acid separates out, and is purified by recrystallisation from hot water, the yellow crystalline product being dried at a temperature not exceeding $100^{\circ} \mathrm{C}$.

Picric acid containing as much as 17 per cent. of water can be detonated by a charge of dry picric powder; a thin layer may also be exploded by a blow between metal surfaces, its sensitiveness to shock being greatly increased by warming, for at a temperature just below its melting point a pound weight falling from a height of 14 inches will explode it.

The sensitiveness of picric acid can be reduced by converting the powder into larger masses, this being accomplished either by granulating it with a solution of collodion cotton in etheralcuhol, as in the earlier forms of mélinite, or by fusion, which takes place some twenty degrees above the boiling point of water, and casting directly into the shell, as in lyddite and possibly the mélinite of the present day. In any condition perfect detonation would yield only colourless gaseous products rich in carbon monoxide, but the bursting of a lyddite shell is frequently accompanied by a yellow smoke, probably formed by undecomposed acid in the form of vapour. The shells appear NO. 1588 , VOL. 6 I] to burst in two distinct ways, in one case giving a sharp powerful explosion with enormous concussion and no yellow smoke, and the other a dull heavy report with the yellow smoke, the two results appearing to be due to perfect decomposition in the first instance, whilst in the second partial decomposition only probably occurs.

Various mixtures of picric acid or its salts, together with some oxidising agent, have been used from time to time, Abel's powder consisting of ammonium picrate, potassium nitrate, and a small quantity of charcoal.

It is impossible to deal with the numerous other explosives which are largely in use in such a survey as this, and therefore attention has been confined to those which play the most active part in modern warfare.

\section{ANTI-PLAGUE INOCULATIONS.}

THE final proof of Chapter iv. of the Indian Plague Com. mission Report, dealing with Haffkine's anti-plague inoculations, has already been briefly referred to (p. 422); the following are further notes upon its contents :-

The first paragraphs contain a brief review of the history of preventive inoculation, the Commissioners trace it up to Haffkine's anti-cholera inoculations, in which a measured quantity of bacteria of known virulence was used. The next practical extension is stated to be the anti-typhoid inoculations introduced by one of the Commissioners (Prof. Wright), in which dead cultures were used; the first of these inoculations were done in July and August r896. Next, they say, come in chronological order the experiments of Yersin, Calmette and Borrel, conjointly in 1895 , which showed it was possible to confer a certain amount of immunity against plague by injection of dead cultures of plague bacilli. Mr. Haftkine's anti-plague inoculations, the Commissioners say, represent an extension of this system of preventive inoculation to men. That Mr. Haffkine was not indebted to Yersin, Calmette and Borrel, nor to the system of anti-typhoid inoculation, for the suggestion to use dead cultures in his plague prophylactic, is evident from the words used by Mr. Haffkine in his lecture on "Anti-Cholera Inoculation" reported in the British Medical Journal, February II, I893: "The microbes introduced under the skin do not propagate, but after a certain time they die and disappear. It is the substances which they contain, and which are set free when they die, that act upon the animal organism and confer immunity upon it. It is found that the same result can be obtained if the microbes be killed before inoculation, and if their dead bodies only be injected." Prof. Wright recognises this, for, in his account of the first anti-typhoid inoculations, Lancet, September 19, I896, he says: "I need hardly point out that these anticholera inoculations have served as a pattern for the typhoid vaccinations detailed above."

Had the Commissioners quoted Mr. Haffkine's experiments with sterilised cultures of cholera bacilli, the anti-typhoid vaccine and the anti-plague prophylactic of Yersin, Calmette and Borrel, would have been shown to be an extension of Haffkine's own anti-cholera vaccine rather than the other way about, as it would appear from the report.

The report goes on to a very stringent criticism of the method of preparing the prophylactic. A certain proportion of bottles were found to be contaminated. In dealing with large quantities of prophylactic, it is not unlikely that some bottles should become contaminated, possibly by some of the corks not being sterile, as Mr. Haffkine suggests. The fact was not brought before the notice of Mr. Haffkine, but was sprung upon the Commissioners and mentioned in the daily Press at the time, with the evident intent to detract from the value of the prophylactic. The Commissioners investigated the matter, but found no serious results could be traced to such accidental contaminations.

The comparative value of the bacterial sediment and of the supernatant fluid is discussed, and, finally, the method of standardisation.

The process of manufacture is criticised from the point of view of scientific manipulation in a properly equipped laboratory for experiments on a small scale. The Commissioners do not mention the fact that the prophylactic is made on a large scale, as much as 20,000 doses being turned out per day, and this in a laboratory with no proper equipment, and with an insufficient and partially inefficient staff. And now having adversely criticised the theory and methods of the General who is conducing 
the campaign against plague, one expects to find some radical alteration advised; but no, they turn round and join forces, saying, "We recognise that even though a vaccine which is in sufficiently standardised, and which is occasionally contaminated, is from the scientific point of view a very imperfect vaccine, yet judged from the standpoint of practical life, such defects may very well be overlooked if the insufficient standardisation and the occasional contamination of the vaccine have not interfered in a sensible manner with its utility.

"This standpoint, which is indeed the only reasonable standpoint, is the standpoint which has been taken up by Mr. Haffkine in the statement that was handed in by him, and which is published, at his request, in our Proceedings."

The second part of the report criticises the statistics of antiplague inoculations. In their summary, the Commissioners say that inoculation diminishes the number of attacks and diminishes the death-rate among those inoculated, that it does not appear to confer any degree of immunity till a few days have elapsed after inoculation, and that the protection lasts certainly for a considerable number of weeks, and possibly for some months.

They recommend that inoculations under safeguards and conditions stated in the report should he encouraged wherever possible, and in particular among disinfecting staffs and attendants of plague hospitals.

C. B. S.

\section{EXPERIMENTAL STUDY OF FERTILISATION.}

IN I898 Prof. Yves Delage made a remarkable experiment. ${ }^{1}$ He divided the unfertilised 'egg of a sea-urchin (Strongy. locentrotus lividus) under the microscope into two parts-one containing the nucleus and the centrosome, the other simply cytoplasmic. Beside these he placed an intact ovum, and then supplied spermatozoa. Towards these the three objects showed equal "sexual attraction"; all three were fertilised; and all three segmented, the intact ovum most rapidly, the nucleated fragment more slowly, the non-nucleated fragment more slowly still. In one experiment, the development proceeded for three days, during which the intact ovum had become a typical gastrula, the nucleated fragment a smaller gastrula, and the nonnucleated fragment a quasi-gastrula with almost no cavity. In each case the cells showed nuclei. The conclusion was then drawn that fertilisation and some measure of development may occur in a fragment of ovum without nucleus or ovocentre, and it was suggested that we have in fertilisation to distinguish two processes:- (a) the stimulus given to the ovum by a specially energetic kinoplasm brought in by the spermatozoon, perhaps in its centrosome; and $(b)$ the mingling of heritable qualities, or amphimixis. One may also note that the experiment was suggestive in furnishing experimental confirmation of what is generally assumed, that each of the sex-cells is a fully equipped potential individuality. Here we may recall the remarkable experiment of H. E. Ziegler," who divided the just fertilised ovum of a sea-urchin in such a way that each half had one pronucleus, and observed that the half with the male pronucleus seg.nented and formed a blastula.

In 1899 Delage continued his experiments, ${ }^{3}$ and with striking success. Non-nucleated fragments of the ova of a species of Echinus, of Dentalium entale, and of Lanice conchilega were effectively fertilised; they proceeded to develop, and gave rise to plutei, veligers, and trochophores respectively. The terms merogonic fertilisation and merogonic development are suggested to express the remarkable facts observed.

The segmentation of the fertilised non-nucleated fragment was practically normal in the sea-urchin, very irregular in Dentalium, less irregular in Lanice (the chief irregularity being lack of correspondence between the nuclear and the cytoplasmic divisions), but as the development proceeded some self-regulative process reduced the abnormalities to insignificance. The plutei only differed from the normal in the extreme reduction of the arms; the veligers and trochophores were almost typical. They showed no lack of vitality, and although further development did not occur, the same is usually true of normal larvæ reared in similar conditions.

I "Embryons sans noyau maternel." C. R. Ac. Sci. Paris, cxxvii. (r8g8), pp. 528-53x.

figs.

3 "Études sur la mérogonie." Arch. Zool. expér., vii. (1899), pp. $3^{8} 3^{-}$ 417, Ir figs. See also C.R. Ac. Sci. Paris, cxic. (1899), pp. 645-648. NO. 1588 , vOL. 61$]$
As to the limits of possible merogony, Delage got some results which are nothing if not striking. A quarter of a Dentalizmovum was fertilised and segmented; abont a fifth of a Laniceovum was successfully treated; but the chef d'auvre of experimental nicety was seen when $1 / 37$ of a sea-urchin ovum gave rise to an agile blastuia. Delage has christened his pigmy creations-tetartogonic, pemptogonic, \&c.--but he seems to hesitate in regard to that arising from the $1 / 37$, for he puts the title "triacosthedomogonique" in a footnote. That there is a limit to merogony he is convinced, but he will not at present fix it. It seems not inappropriate to recall Marchal's description ${ }^{1}$ of the strange behaviour of the ovum of Encyrtus fuscicollis (one of the parasitic Hymenoptera), which gives rise to a legion of morulæ, and forms a chain of 50-100 embyros within one elongated amniotic envelope. For practical purposes it is convenient to remember that, just as four lancelet embyros may be got by shaking apart the first four blastomeres, so Delage by cutting a sea-urchin ovum obtains three larvæ from one egg.

The issues involved in these experiments are so serious (biologically) that one is naturally led to consider possible criticisms, which Delage in his candid scientific spirit has himself suggested. It is difficult to refrain from the suspicion that there may have been some mistake somewhere. The best criticism would, of course, be to repeat the experiments; but in default of this, let us briefly consider with the author some of the possibilities of error. (a) It may be suggested that the eggs experimented with had been previously fertilised by stray spermatozoa; but Delage's experience has been that the spermatozoa die $24-36$ hours after liberation; and the water in which the eggs were placed had stood for three or four days in a stone cistern. Moreover, only in one case was segmentation seen among the eggs from which those experimented upon were. taken. (b) It may be suggested that the segmentation of the fertilised non-nucleated ovum-fragments was not genuine, but a pathological fragmentation such as is occasionally observed after mechanical or chemical stimulation; but it must be remembered that larvæ were reared, and there were, of course, control observations on non-fertilised fragments. (c) It may be suggested that the nucleus was cut in the delicate operations, so that each part had really a portion of nucleus as well as cytoplasm. But it must be remembered that the nucleus is very small and very mobile, and thus runs little chance of being cut; in the clear ova of the sea-urchin it was sometimes seen after the operation in the larger part, only once in the smaller part, never in both. In the other two cases (Dentalium and Lanice) the opacity of the egg hides the nucleus. Perhaps the best answer is, that in one experiment three embryos were got from one ovum, and that fragments representing $\mathrm{I} / \mathrm{ro}$ and $\mathrm{r} / 37$ of the total volume of the egg were also seen to segment. It seems, however, possible still to retort that the operation broke the nucleus and caused a distribution of nucleoplasm into the various fragments before they were quite separated.

What are the conditions of successful merogony? Delage failed with the ova of Ciona, Haliotis, Chiton, Sabellaria, \&c., and he almost failed with those of Lanice until he learned the particular "tour de main" in cutting them. The experiment is not practicable except with eggs which are liberated separately before fertilisation. It usually fails if there is a shell. The ova to be tried by other experimenters should be naked or with a delicate glairy envelope, not too brittle, of firm consistence, and not less than $1 / 10 \mathrm{~mm}$. in diameter. In all Delage's experiments there was a certain percentage of failure, due perhaps to the inability of the fragments to recover from their wounds, or to a diminution in the viscous substance which surrounds the ovum and keeps its parts together. But, in spite of these failures, the number of merogonic segmentations was generally at least equal to, and sometimes greater than, the number of segmentations among intact ova in similar conditions, - - a remarkable fact which leads Delage to the daring suggestion that the absence of the female pronucleus may favour fertilisation. "The female pronucleus is perhaps useful in securing for the embryo the advantages of amphrmixis, but it is not useful in fertilisation nor necessary for the development of the parts of the organism."

The preceding paragraphs give the gist of Delage's remarkable experiments, but there are some less secure addenda which deserve notice. He has shown the possibility of merogonic hybridisation; he observed phenomena which point to a

1 C. R. Ac. Sci. Paris, cxxxvi. (1898), pp. 66́-664. Ann. Nat. Hist. ii. pp. $28-30$. 